\title{
The Effect of Laser Beam Wobbling Mode on Weld Bead Geometry of Tailor Welded Blanks
}

\author{
${ }^{1}$ Celalettin YUCE* \\ ${ }^{* 1}$ Faculty of Engineering and Natural Science, Department of Mechatronics Engineering Bursa Technical University, \\ Turkey
}

\begin{abstract}
As a higher weight leads to increased fuel consumption for the automobile industry, the body in white must be lighter to compensate for the weight of additional components. Therefore, tailored blanks are used, which reinforce the body in white only in areas where a higher strength or stiffness is necessary. The applicability of laser welding processes with its numerous advantages, such as low heat input and production efficiency, is often limited when joining imperfect edges steel sheets due to small gap bridging ability. To overcome this limit, recent developments in the laser industry have introduced a novel method to wider the applications of lasers through the utilization of fast beam oscillation techniques, also known as laser beam wobbling. In this study, the effects of the four different amplitudes $(0.5 \mathrm{~mm}, 1 \mathrm{~mm}, 1.5 \mathrm{~mm}$ and $2 \mathrm{~mm})$ of circular laser beam oscillation patterns on the weld bead geometry and microhardness distribution were investigated. The results revealed that the weld bead width increased with the increase of wobble amplitude. Moreover, the tensile strengths of the welded blanks were higher than the AHSS base metal for all amplitude levels.
\end{abstract}

Key words: Laser beam welding, beam oscillation, Tailor blanks, Gap bridging ability

\section{Introduction}

The automotive sector is focused on developing fuel-saving, higher safety vehicles with costefficient manufacturing methods. This will be achieved through proper design and using lighter and stronger materials on the auto body parts. The introduction of tailor-welded blanks (TWB) in the automotive industry has allowed the optimization of vehicle weight and the reduction of fuel consumption and emissions. The TWB idea was first born to reduce cost by means of using leftover bits and pieces of sheet metal to produce side inner panels by Honda in the 1960s [1]. TWB is created by the laser welding of multiple steel sheets of different grades, thicknesses, or coating types, which are then formed to the desired component. Thus, the thickness of a formed component can be tailored to the local requirements for strength and stiffness, and thus, its excess weight can be avoided. In the automotive industry, steel tailor-welded blanks are used to provide optimum strength using the least amount of material possible for specific points on a vehicle. The major application is with steel TWB sheet for automotive components such as body-side frames, door inner panels, motor compartment rails, center pillar inner panels, and wheelhouse/shock tower panels. The method is under continued development, especially for new steel grades in the automotive industry.

*Corresponding author: Address: Faculty of Engineering and Natural Science, Department of Mechatronics Engineering Bursa Technical University, 16310, Bursa, TURKEY. E-mail address: celalettin.yuce @btu.edu.tr 
Among various welding methods, laser welding is playing a vital role in the joining of TWBs due to its flexibility, high energy density, high welding speed, smaller heat-affected zone (HAZ), and low deformation [2]. The microstructures of joints are transformed locally under the welding process due to the thermal cycles, and then the mechanical properties change correspondingly. Several researchers investigated the effects of process parameters on the mechanical and metallurgical properties of laser-welded Ultra High Strength Steel (UHSS) and Advanced High Strength Steel (AHSS) blanks. Xing et al. [3] investigated microstructure, microhardness profile, tensile behavior, and formability of DP1180 tailor-welded blanks. Razmpoosh et al. [4] aimed to characterize the microstructural evolution and mechanical behavior of dissimilar laser joints of the third-generation AHSSs. Yuce et al. [5] optimized process parameters of fiber laser welded dissimilar high strength low alloy (HSLA) and martensitic steel (MART) steel using a Taguchi approach. They stated that, if the heat input level was not sufficient due to high speed or low laser power, the weld bead geometry was not formed appropriately. Zhao et al. [6] reported that reduced welding speed led to a large martensite decomposition degree and a high degree of softening and that welding speed directly affected the softening degree.

Besides various advantages, there are, however, also some problems, which create some difficulties in dealing with the laser welding of UHSS and AHSS steels, especially butt joint formation. The quality of the welded joints depends significantly on the preparation of the edges of components for welding. Due to the small spot size of the laser beam, when the gap between the parts to be joined is not controlled, penetration problems are observed, and the joint is not at the desired quality [7]. Recent developments in the laser industry have introduced a novel method to wider the applications of lasers through the utilization of fast beam oscillation techniques, also known as laser beam wobbling. Wobble effect is produced by high-frequency wobbling rotation of the optic lens, which in turn produces a laser beam that moves in various modes. Common laser beam oscillation patterns are sketched in Fig. 1. Compared to conventional laser welding methods, laser beam wobbling results in superior weld quality, especially in butt weld formation, with different gaps between the samples.
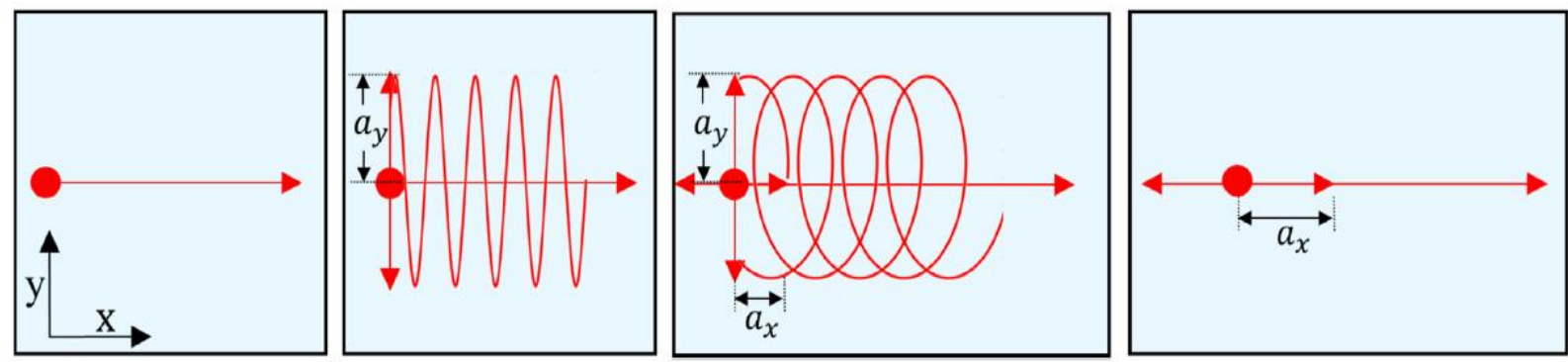

Figure 1. Schematic diagrams of common laser beam oscillation patterns, a) without oscillation, b) transverse oscillation, c) circular oscillation, d) longitudinal oscillation [15].

Goebel et al. [8] used a circular laser beam oscillation pattern and filler wire for narrow gap welding of thick aluminum sheets by a multi-pass welding method. They observed that with beam oscillation, the position tolerance of the filler wire could be increased significantly. Grünenwald et al. [9] conducted a high-power fiber laser welding with beam oscillation to produce bead on plate welds to investigate the influence of the oscillation frequency on the shape of the weld cross- 
section. Schultz et al. [10] investigated the influence of the welding speed, wire feed speed and beam oscillation parameters on wire melting behavior. They stated that, after a successful process initialization, the gap bridging ability increased significantly to $315 \%$ of the sheet thickness. Hao et al. [11] showed the effects of laser beam oscillation parameters on the laser-welded austenitic stainless steel joints. Wang et al. [12,13] stated that the laser beam oscillation stabilized the welding process and improved the welding morphology. Kuryntsev and Gilmutdinov [14] investigate the influence of the second wobbling laser welding pass on microstructure and mechanical properties of structural steel. The results show that, with the wobbling trajectory of the laser beam, middle and cap parts of the seam have a lower microhardness in relation to the root part.

The present study aimed to investigate the effects of circular wobbling on the gap bridging ability and weld bead dimension of fiber laser welded UHSS and AHSS steel. For this purpose, four different amplitude levels $(0.5 \mathrm{~mm}, 1 \mathrm{~mm}, 1.5 \mathrm{~mm}$, and $2 \mathrm{~mm})$ investigated in butt welding geometry. The weld appearance, metallurgical, and mechanical properties of the butt-welded joints are analyzed comparatively.

\section{Materials and Method}

In this study, ultra-high-strength (DP1180) and advanced high strength (DP600) steels with thicknesses of 1.2 and $0.8 \mathrm{~mm}$, respectively, are used in the experiments. The samples were sheared into coupons, which had the sheared edges placed together for conducting welds in butt joint configuration. Photographs of the welding fixture and welded samples were shown in Fig 2. The mechanical and chemical properties of the materials are shown in Table 1.
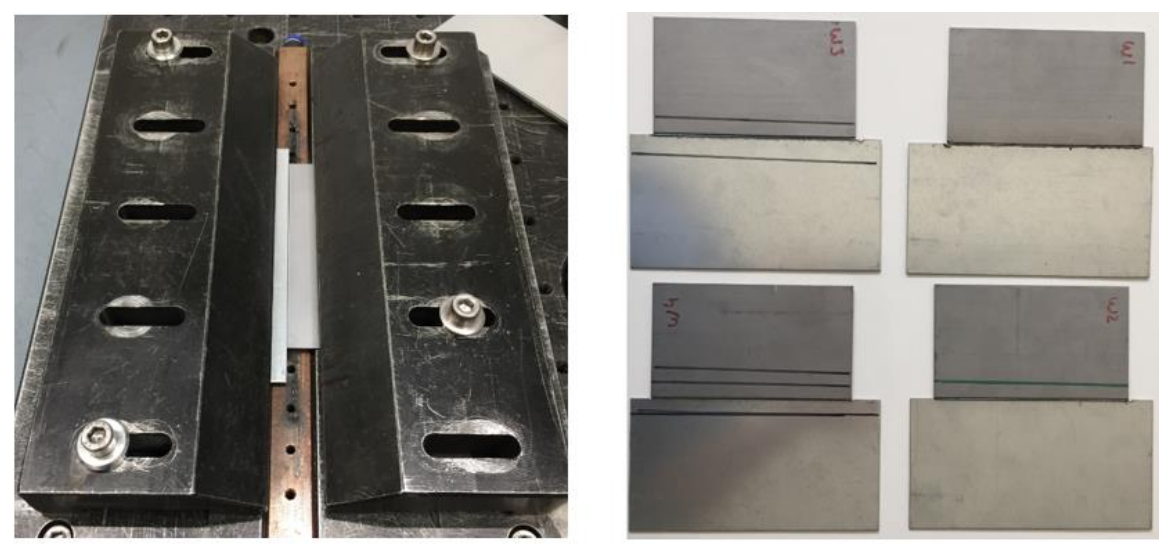

Figure 2. Photographs of the welding fixture and welded samples. [15].

Table 1. Mechanical properties and chemical composition of the steels

\begin{tabular}{ccccccccc}
\hline Material & $\mathbf{C}$ & $\mathbf{S i}$ & $\mathbf{M n}$ & $\mathbf{P}$ & $\mathbf{S}$ & $\begin{array}{c}\text { Yield Strength } \\
(\mathbf{M P a})\end{array}$ & $\begin{array}{c}\text { Ultimate } \\
\text { Strength (MPa) }\end{array}$ & $\begin{array}{c}\text { Elongation } \\
(\mathbf{m i n} \%)\end{array}$ \\
\hline DP1180 & 0.23 & 1 & 2.9 & 0.05 & 0.01 & $800-970$ & $1180-1300$ & $\geq 8$ \\
DP600 & 0.04 & 0.48 & 1.4 & 0.02 & 0.01 & $270-330$ & $640-660$ & $\geq 23$ \\
\hline
\end{tabular}


The IPG ytterbium fiber laser attached to an ABB robotic arm was used for welding experiments. The maximum power of the laser was $4 \mathrm{~kW}$, and the wavelength was $1070 \mathrm{~nm}$. The laser transmitted through the fiber optic cables and then came to a wobbler head. The fiber laser had a fiber core diameter of $0.2 \mathrm{~mm}$ with a laser beam spot size of $0.4 \mathrm{~mm}$. The focal length was 200 $\mathrm{mm}$. During the fiber laser welding process, no shielding gas was used. Furthermore, trial experiments were applied to determine the operating range of each process parameter in order to produce acceptable quality welding.

AHSS and UHSS samples were welded at a constant laser power and welding speed of $2 \mathrm{~kW}$ and $70 \mathrm{~mm} / \mathrm{s}$, respectively. The welding process was investigated for a circular beam oscillation pattern (Fig 3). In order to achieve a circular laser beam oscillation pattern, the frequencies and the amplitudes were identical for both the $\mathrm{x}$ and $\mathrm{y}$-axis. The circular oscillation frequency was $290 \mathrm{~Hz}$, and the effect of amplitudes was investigated for four different levels of wobble amplitudes $(0.5$ $\mathrm{mm}, 1 \mathrm{~mm}, 1.5 \mathrm{~mm}$, and $2 \mathrm{~mm})$.

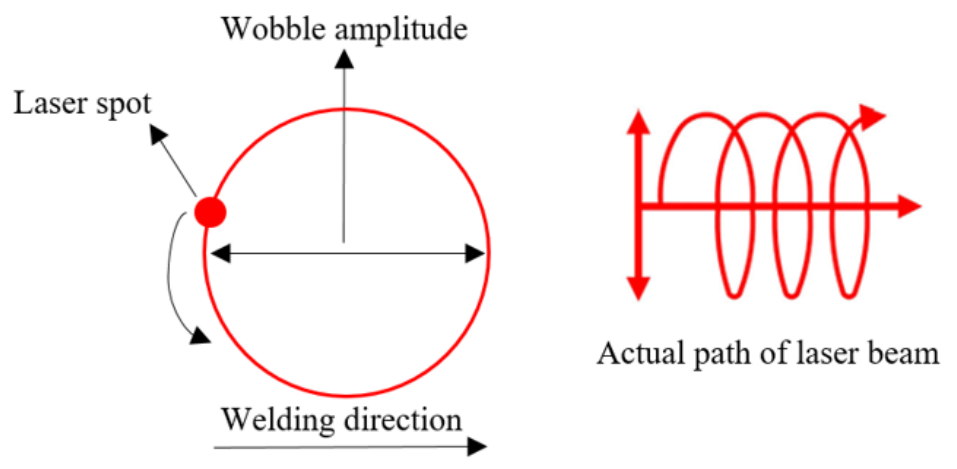

Figure 3. Schematic diagrams of applied circular oscillation patterns and the resulting trajectory of the laser beam path.

At the metallographic examination stage, the samples were cut from the weld cross-section using an electrical discharge cutting machine, then mounted in Bakelite, ground, and polished with diamond paste. The samples were etched for revealing microstructure with $3 \%$ Nital solution. Then, samples were analyzed for microstructural changes and possible defects using an optic microscope with an image analysis system. Vickers microhardness measurements were performed with a 200 $\mathrm{g}$ load, and $10 \mathrm{~s}$ dwell time. Tensile samples were machined from the perpendicular to the welding direction in accordance with ASTM, E8/E8M. Tensile tests were performed using a computerized tensile testing machine using a constant crosshead speed of $5 \mathrm{~mm} / \mathrm{min}$.

\section{Results and Discussions}

In this study, the effects of the four different amplitudes $(0.5 \mathrm{~mm}, 1 \mathrm{~mm}, 1.5 \mathrm{~mm}$ and $2 \mathrm{~mm})$ of circular laser beam oscillation pattern on the weld bead geometry and microhardness distribution were investigated. Weld bead geometry, which means the bead width and penetration depth, is an essential physical characteristic of a weldment, especially for butt welded samples. It was observed that the amplitude of the laser beam was an effective parameter that affects the weld width. Fig. 4 
showed the influence of the amplitude on the weld bead geometry in welding $0.8 \mathrm{~mm}$ thick AHSS and $1.2 \mathrm{~mm}$ thick UHSS sheets, at otherwise constant process parameters (laser power $2 \mathrm{~kW}$, welding speed $70 \mathrm{~mm} / \mathrm{s}$ and oscillation frequency $290 \mathrm{~Hz}$ ).

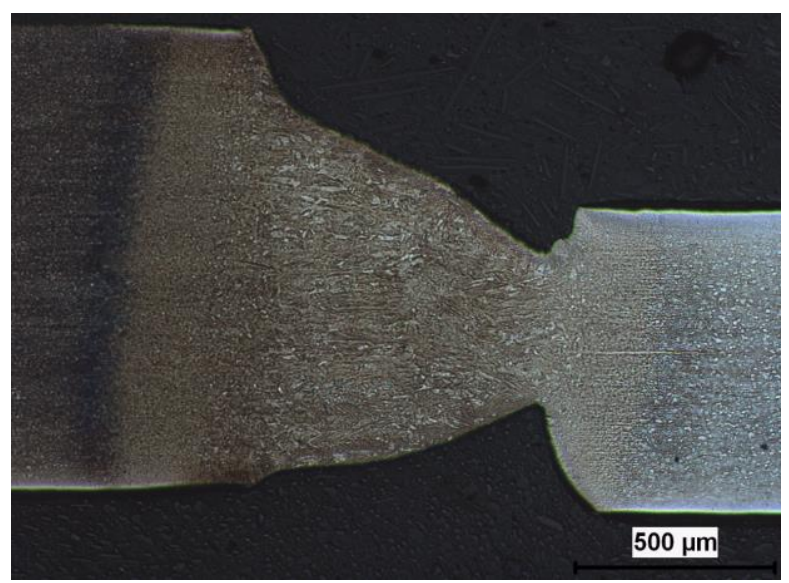

a)

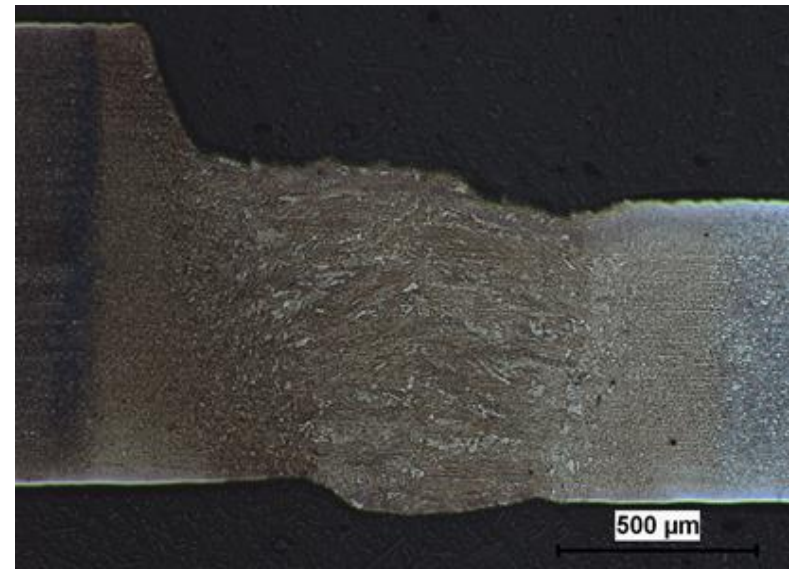

b)

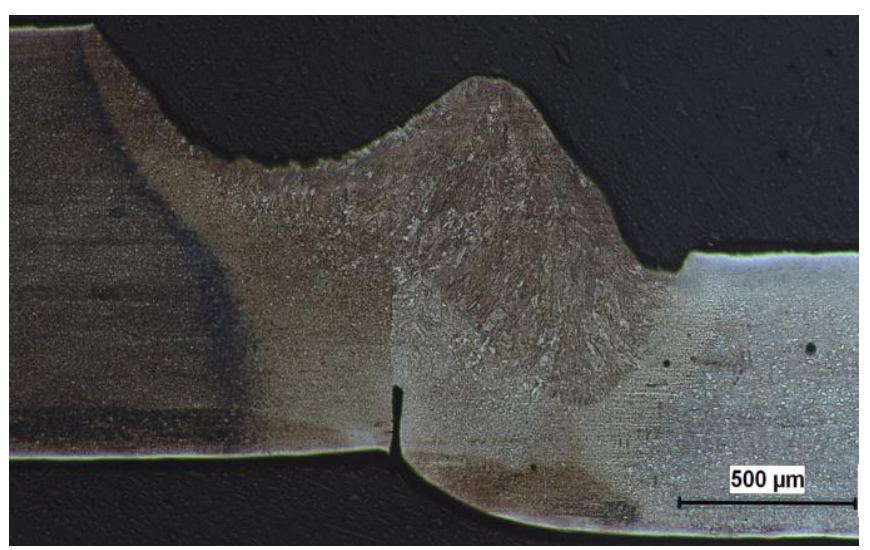

c)

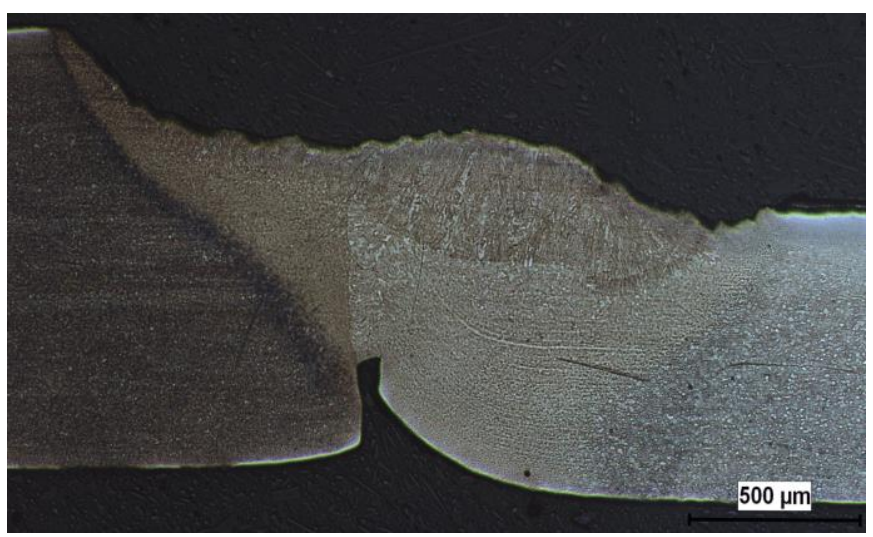

d)

Figure 4. Cross sectional views of welded samples with different amplitudes; a) $0.5 \mathrm{~mm}, \mathrm{~b}) 1 \mathrm{~mm}, \mathrm{c}) 1.5 \mathrm{~mm}$ and d) $2 \mathrm{~mm}$. 
The corresponding cross sections of laser beam welded with circular oscillation pattern joints with varied wobble amplitudes were shown in Fig. 4. The variation of the amplitude was operated by varying the laser beam while retaining other process parameters. At the equal laser power, welding speed, and oscillation frequency levels, increasing the amplitude resulted in a wider weld zone and, consequently, lower penetration depth. There was an appropriate correlation between the weld width, and wobbler amplitude was obtained. At the maximum amplitude level ( $2 \mathrm{~mm})$, a maximum of $2027 \mu \mathrm{m}$ weld width was measured (Fig. 4d). The minimum weld width was obtained at an amplitude of $0.5 \mathrm{~mm}$, which was $810 \mu \mathrm{m}$ (Fig. 4a). The measured weld widths for all amplitude values were given in Fig. 5.

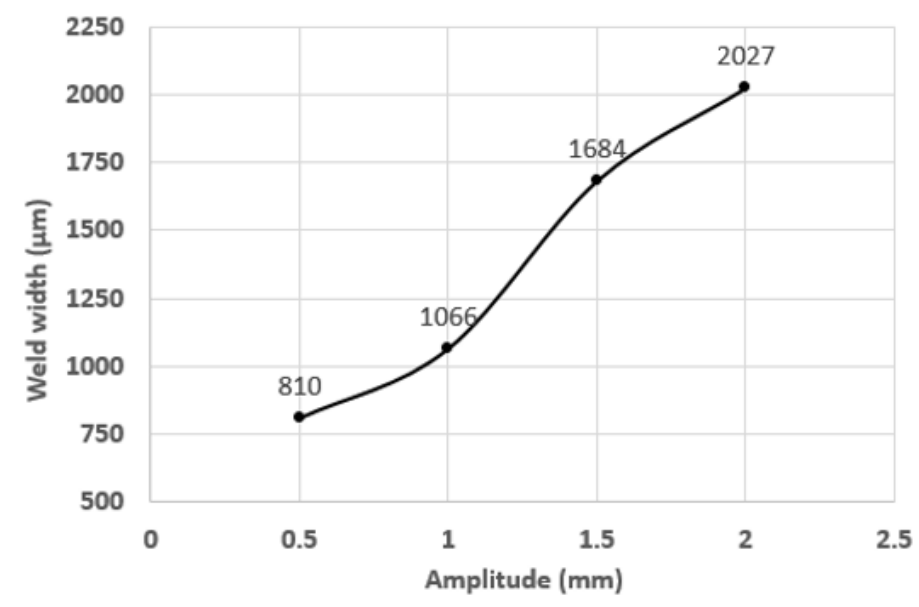

Figure 5. Effect of wobble amplitude on the weld bead width.

In order to determine the microhardness distribution profiles along with the weld bead for the four different wobble amplitude levels, the Vickers microhardness tests were carried out. The measurement traversed the weld-seam from AHSS to UHSS. The distance between each measurement point was $0.25 \mathrm{~mm}$. The line where the hardness measurements were conducted is indicated by a yellow line on the optical microscope image. As can be seen in Fig. 6, the two base materials were clearly identified at the left- and right-sides of the plot. Each exhibits an almost constant hardness. The microhardness of the BM of the DP600 and DP1180 steels was measured as 237 and 442 Vickers, respectively. Due to the higher martensite content, the average microhardness of DP1180 was higher than that of DP600. In the HAZ region of the AHSS steel, the hardness value varied. Where the region near the weld zone (WZ) had a higher hardness than the region close to the base metal (BM) due to the formation of martensite. At the maximum amplitude level $(2 \mathrm{~mm})$, due to the lower heat input and shallow penetration depth, the hardness values of the WZ was lowest. Maximum WZ hardness was observed on the $1 \mathrm{~mm}$ amplitude level. Martensite formation was observed in this sample as a result of full penetration and rapid cooling. 


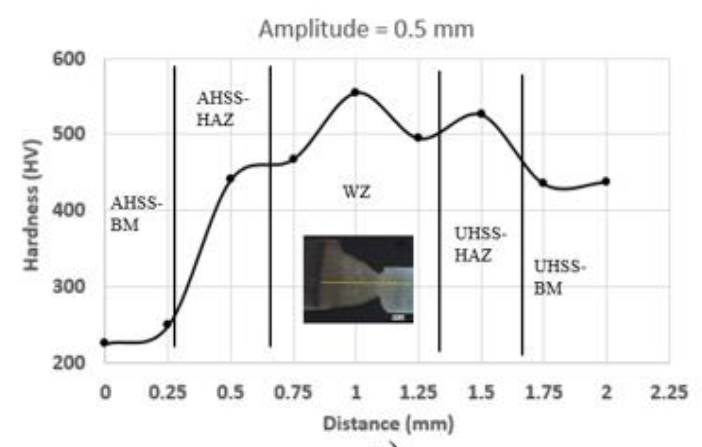

a)

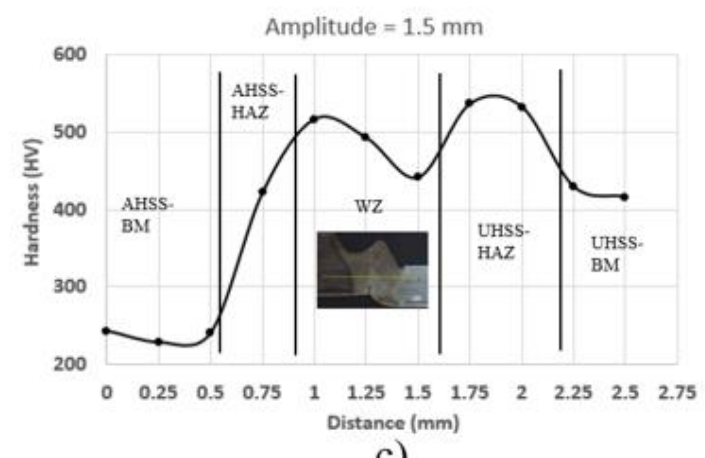

c)

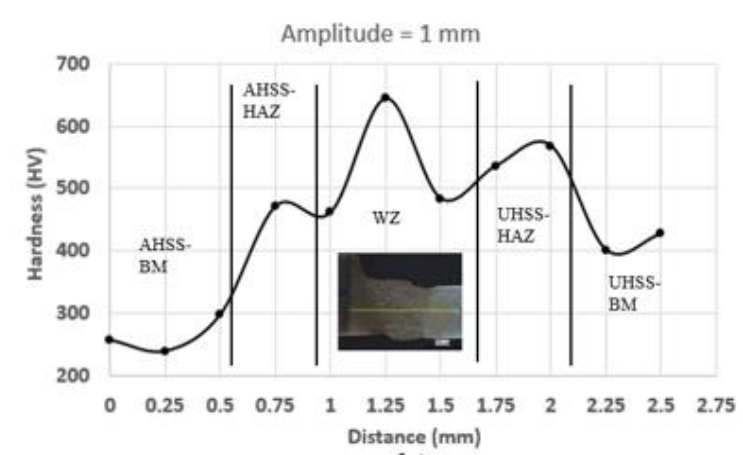

b)

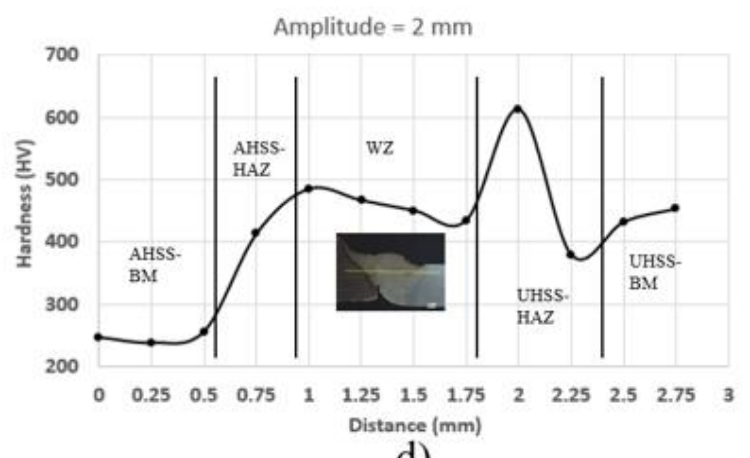

d)

Figure 6. The micro-hardness distribution profiles for different wobble amplitude levels input levels; a) $0.5 \mathrm{~mm}$, b) 1 $\mathrm{mm}$, c) $1.5 \mathrm{~mm}$ and d) $2 \mathrm{~mm}$.

From the welded joints, three tensile test specimens were prepared by the electrical discharge cutting technique for all amplitude levels, and tensile tests were conducted to evaluate the strength of the welded dissimilar joints. The results of the tests showed that for all amplitude levels, tensile strength was higher than the DP600 base material. The fracture of tensile specimens of the welded blanks always occurred in the DP600 side (Fig. 6). Both the welded joints showed basically similar features on the fracture surfaces. Cup-like dimple rupture was the main feature of the fracture surface, representing the ductile type of fracture mode.

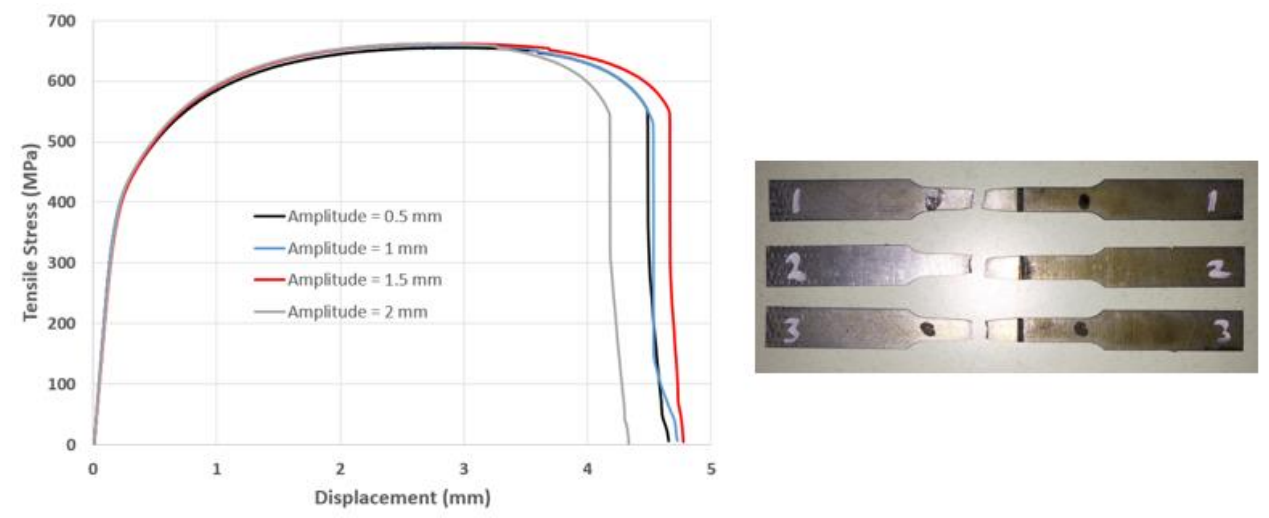

Figure 7. Tensile stress-displacement and typical failure location of the tensile test samples of the laser welded blanks. 


\section{Conclusions}

This study evaluated the effects of circular laser beam oscillation on fiber laser tailored blank weldability of UHSS and AHSS (DP 1180 and DP 600, respectively) automotive steels. The samples have been evaluated with respect to weld bead geometry, tensile properties, gap bridging ability, and microhardness profile. In conclusion, the study can be summarized as the wobbling amplitude greatly influences the aspect ratio of the weld seam. With lower wobbler amplitude values, the weld width was increased, and its penetration was decreased. Laser beam wobbling higher amplitude levels provides an advantage in joining surfaces that are not properly prepared. Due to the edge preparation and the limited required gap are certainly much-felt issues in the automotive industry, such characteristics must be kept under control to grant a correct fusion of both edges, due to the small size of the laser beam. In the tensile tests of the welded samples, no changes were observed in the selected amplitude values. All amplitude values of the tensile fracture occurred at the base metal of the AHSS. The micro-hardness profiles of the joints showed that, at the maximum amplitude level $(2 \mathrm{~mm})$, due to the lower heat input and shallow penetration depth, the hardness values of the weld zone was lowest. Finally, the application of this laser beam oscillation technique might limit the need for monitoring and control of the edges. It allows increasing the tolerance interval required for the gap preparation among the parts, a very critical aspect in laser welding.

\section{Acknowledgements}

This work was carried out utilizing laser welding equipment of the IPG Photonics Eurasia at Gebze, Türkiye. The authors would like to thank Mr. Hakan DEMİR for his help.

\section{References}

[1] Gong, H., Wang, S., Knysh, P., Korkolis, Y.B. (2016) "Experimental investigation of the mechanical response of laser-welded dissimilar blanks from advanced- and ultra-high-strength steels", Materials and Design 90, 1115-1123.

[2] J.H. Lee, S.H. Park, H.S. Kwon, G.S. Kim, C.S. Lee, (2014) "Laser, tungsten inert gas, and metal active gas welding of DP780 steel: comparison of hardness, tensile properties and fatigue resistance", Mater. Des. 64, 559-565.

[3] Xing, F., Qiu, X., Zhao, L., Ruan, Y., Wang, D. (2019) "Hardening, Softening, and Mechanical Properties in Ultra-High-Strength DP1180 Tailor-Welded Blanks" Journal of Materials Engineering and Performance volume 28, 2086-2093.

[4] Razmpoosh, M.H., Macwan, A., Biro, E., Zhou, Y. (2020) "Microstructure and dynamic tensile characteristics of dissimilar fiber laser welded advanced high strength steels" Materials Science \& Engineering A 773, 138729.

[5] Yuce, C., Tutar, M., Karpat, F., Yavuz, N. (2016) "The Optimization of Process Parameters and Microstructural Characterization of Fiber Laser Welded Dissimilar HSLA and MART Steel Joints", Metals 6, 245.

[6] Y. Zhao, Y. Zhang, W. Hu, Effect of welding speed on microstructure, hardness and tensile properties in laser welding of advanced high strength steel, Sci. Technol. Weld. Join. 18 (7) (2013) 
581-590.

[7] Bachmann, M. Gumenyuk, A., Rethmeier, M. (2016) "Welding with High-power Lasers: Trends and Developments", Physics Procedia, 83, 15-25.

[8] Goebel, G., Brenner, B., Beyer, E., (2007) "New application possibilities for fiber laser welding", ICALEO 2007-26th International Congress on Application of Lasers \& Electro-Optics, Orlando (FL) USA.

[9] Grünenwald, S., Unt, A., Salminen, A. (2018), "Investigation of the influence of welding parameters on the weld geometry when welding structural steel with oscillated high-power laser beam", Procedia CIRP 74, 461-465.

[10] Schultz, V., Seefeld, T., Vollertsen, F. (2014) "Gap bridging ability in laser beam welding of thin aluminum sheets", Physics Procedia 56, 545 - 553.

[11] Hao, K.; Li, G.; Gao, M.; Zeng, X. (2015) "Weld formation mechanism of fiber laser oscillating welding of austenitic stainless steel", J. Mater. Process. Technol. 225, 77-83.

[12] Wang, L.; Gao, M.; Zhang, C.; Zeng, X. Effect of beam oscillating pattern on weld characterization of laser welding of AA6061-T6 aluminum alloy. Mater. Des. 2016, 108, 707-717. [13] Wang, L.; Gao, M.; Zeng, X. (2019) "Experiment and prediction of weld morphology for laser oscillating welding of AA6061 aluminium alloy”, Sci. Technol. Weld. Join. 2019, 24, 334-341.

[14] Kuryntsev, S., Gilmutdinov, A.K. (2015), "The effect of laser beam wobbling mode in welding process for structural steels", Int J Adv Manuf Technol. 81:1683-1691.

[15] Fetzer, F., Sommer, M., Weber, R., Weberpals, J., Graf, T. (2018) "Reduction of pores by means of laser beam oscillation during remote welding of AlMgSi", Optics and Lasers in Engineering 108, 68-77. 